\title{
搭载 POS 数据的无人机影像提高定位精度的方法
}

\section{The Method of Improving Positioning Accuracy of UAV Image with POS Data}

\section{田鹏}

Peng Tian

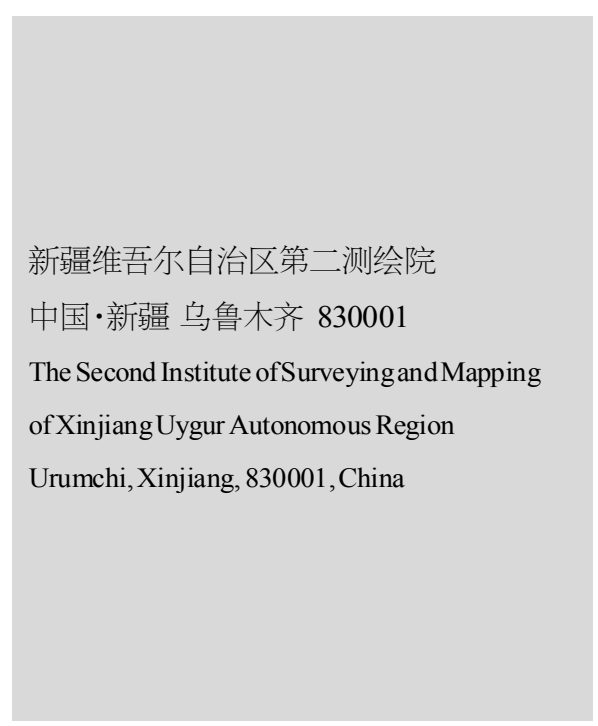

\section{1 遥感定位模型构建}

\section{1 控制系统}

控制系统的作用是通过对航线实施有效的规范，同时对 飞行路线加以设置，与此同时，这一系统能够对路线进行控 制, 所以, 控制系统能够对无人机的飞行情况加以干预。

\section{2 遥感平台}

遥感平台的作用是: 承载传感器, 保证其对地面目标进行 探测, 并且对数据信息进行及时、快速的传输, 以便能够提供 技术保障。无人机遥感平台, 在一般情况下,主要通过小型飞 机平台、飞行控制系统组成 ${ }^{[1]}$

\section{3 影像处理平台}

这一平台要对无人机传回的数据加以分析, 并且要保证 数据的有效性和合理性, 此外, 还应该加强图片的融合能力, 确保其具有更多的功能, 通常包括以下几方面: 汶览和查询功 能。在对轻小型无人机进行操作的过程中, 首先, 要对地面加 以监测,进而完成区域定位, 基于这一现状,进而实施有效的 规划、设计航线。此外, 将设计结果传输到飞行平台, 从而对地 面加以拍摄, 获取有效的影像。

\section{2 无人机坐标系构建}

对于轻小型无人机而言, 进行目标定位往往要凭借传感
器。一般而言, 主要的传感器为图像传感器。由于其在运行的 过程中, 会受到空气流的影响, 因此, 不能按照规划的路线进 行有序的飞行,这就使得在定位的过程中, 会出现偏航角、翻 滚角偏差, 同时定位的连续性也有一定的影响,进而使得目标 定位存在一定的误差。对于轻小型飞机而言,具有以下优势： 当起飞一段时间仍然可以获取有效的信息,主要原因是:通过 转换视角对起飞点进行定位，基于这一现状，能够构建坐标 系, 进而获取数据信息 ${ }^{[2]}$ 。

\section{3 误差消除分析}

\section{1 误差}

通过上述的分析可知，小型无人机定位出现的成像效果， 并定位相关目标, 原理如图 1 所示。

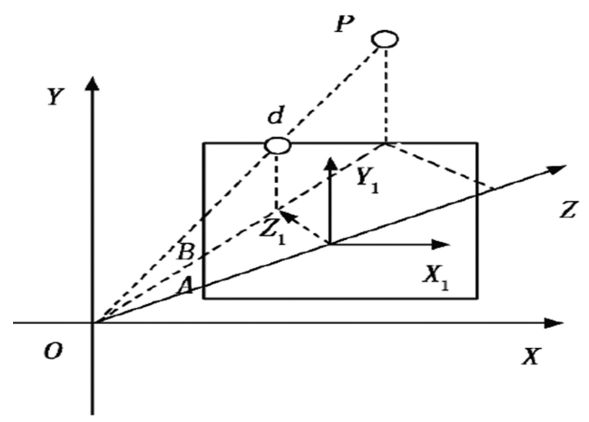

图 1 目标定位原理 
摄影测量 Photogrammetry

经共轴电视图像可以准确确定目标的实际位置, 如果无 人机出现姿势误差问题, 这时就要对目标位置加以修正, 参考 公式如下:

$$
\left\{\begin{array}{l}
A=A^{\prime}-(c-\Delta c) \\
B=B^{\prime}(A+\Delta A)-(B+\Delta B)
\end{array}\right.
$$

\section{2 转换坐标}

通过对目标位置进行有效的转换，这样就可以减少不必 要的误差,再者,如果飞机拉开了较大距离后, 就应该再次获 取其位置。对于这种坐标系模型而言, 以及相应的无人机飞行 特征,可以有效获取相应的数据信息,进而有利于工作人员进 行及时的参考, 从而能够建立与地图相符合的坐标系, 在操作 无人机的过程中, 指挥官应该树立起高度的责任意识, 及时、 全面地确认无人机相关信息, 基于这一现状, 要及时汇总数据 信息, 以便确定目标。此外, 还要重点关注参照物的要求, 并且 进行实时的标记 ${ }^{[3]}$

\section{3 误差消除的实现}

对于原来的无人机定位而言，大多数是把自身当做初始 点, 基于这一情况, 进行合理的转变, 因为这一技术往往存在 误差, 原因在于目标定位不准确。在具体的选择中, 往往以固
定建筑为主。然而, 在这一过程中, 主要的误差在于:图像抖 动、延迟等 ${ }^{[4]}$

\section{4 结语}

通过上述的分析可知, 精准的定位是确保无人机遥感技 术应用的前提, 这一技术是否可以进行有效的测量, 对目标定 位有着重要的影响。按照研究表明, 技术精确度高, 并且对技 术实施研究, 是当今工作人员的主要任务。此外, 这一技术具 有广阔的发展前景 ${ }^{[5]}$ 。

\section{参考文献}

[1]贾金杨,树文,张志华,等.搭载 POS 数据的无人机影像提高定 位精度的方法[J].遥感信息,2019,34(4):92-96.

[2]贾向东.城市 CORS 辅助的无人机影像免像控处理方法研究 [D].北京:中国矿业大学,2019.

[3] 杨光. 基于全局式 SFM 的无人机影像外方位元素优化方法 [D].关州:战略支援部队信息工程大学,2018.

[4]薛武.无人机影像定位优化技术研究[D]. 郑州:战略支援部队 信息工程大学,2017.

[5]张勇.架空输电线路障碍物巡检的无人机低空摄影测量方法 研究[D].武汉:武汉大学,2017. 